\title{
Factors Affecting Survival in Egyptian Patients with Advanced Vulval Cancer
}

\author{
Ahmed Aly Nagy", Ahmed Nader \\ Department of Clinical Oncology, Ain Shams University, Cairo, Egypt \\ Email address: \\ ahmedalynagy@yahoo.com (A. A. Nagy), ahmedelguindy1990@gmail.com (A. Nader) \\ ${ }^{*}$ Corresponding author
}

\section{To cite this article:}

Ahmed Aly Nagy, Ahmed Nader. Factors Affecting Survival in Egyptian Patients with Advanced Vulval Cancer. Cancer Research Journal. Vol. 8, No. 2, 2020, pp. 36-41. doi: 10.11648/j.crj.20200802.13

Received: May 9, 2020; Accepted: May 27, 2020; Published: June 8, 2020

\begin{abstract}
INTRODUCTION: Vulvar carcinoma accounts for about $4 \%$ of the female reproductive tract cancers and a total of $0.6 \%$ of all malignant cancers in females. PATIENTS AND METHODS: This retrospective study aimed to identify the possible risk factors which can impact survival in Egyptian patients with vulval cancer who received treatment at Ain Shams University department of clinical oncology and nuclear medicine in the period from 1-1-2007 till 1-1-2012. RESULTS: Our study included 64 patients [median age 63 years, median overall survival (OS) was 16.5 months]. The factors associated with favourable impact on OS were: Rural residence ( 17 versus 10 months for patients from urban residence, $\mathrm{p}=0.002$ ), premenopausal status ( 19 versus 16 months in post menopausal patients, $p<0.001$ ), low grade histology ( 19 versus 10 months in patients with high grade, $p<0.001$ ) and negative resection margins ( 19 versus 10 months in case of positive margin, $\mathrm{p}<0.001$ ). The factors associated with poor OS were: higher number of offspring ( $\geq 5$ offspring, OS 10 versus 19 months if less than 5 offspring, $p<0.001$ ), patients presenting with ulcer rather than mass ( 11 versus 19 months, $p<0.001$ and those with bilateral disease ( 10 versus 17 months in unilateral disease, $\mathrm{p}=0.04$ ), presence of $\geq 4$ positive groin lymph nodes metastases ( $\mathrm{OS}=16$ months versus 17 months, $\mathrm{p}=0.047$ ) tumor size $\geq 4 \mathrm{~cm}$ ( 10 versus 17 months in case of $<4 \mathrm{~cm}, \mathrm{p}=0.001$ ) and depth of stromal invasion ( 17 versus 16 months in case of $<1 \mathrm{~cm}$ and $\geq 1 \mathrm{~cm}$ respectively, $\mathrm{p}=0.015$ ) CONCLUSION: Urbanization has been linked with more aggressive disease leading to decrease of OS. The age of onset of intercourse did not affect survival as was expected however multiple offspring which could be related to more frequent intercourse had an effect on survival. The offered treatment modalities did not show a superiority probably because all the patients presented in an advanced stage. The anatomical nature of this cancer might be the cause in delayed diagnosis which warrants health education projects for early detection. Further studies are required to assess the risk factors for development of vulval cancer in Egyptian patients.
\end{abstract}

Keywords: Vulva, Cancer, Retrospective

\section{Introduction}

Invasive vulvar carcinoma is considered to be one of the rare cancers of female reproductive tract accounting for about $4 \%$ of the female genital cancers and $0.6 \%$ of all malignant cancers reported in females. Vulval cancers are reported in about 2.5 per 100,000 women years in the developed countries, unfortunately, this cancer is 2-3 times more frequent in the developing world. [1] According to the American Cancer Society, in 2018, there were about 6000 recorded new cases of vulvar cancer and about 1,200 estimated mortalities. The five-year survival rates for vulvar cancer is expected to be 70\%. [2] On the other hand, in Egypt, the crude incidence rates per 100,000 is about $0.3 \%$. [3]

Vulvar carcinoma usually occurs in postmenopausal females with a notable surge in the age-specific incidence with age (50-70 years of age). The labia majora were found to be the most common anatomical site for origin of vulval tumors. The most common histology seen in vulvar cancers is squamous cell carcinoma (SCC) accounting for $90-95 \%$ of the cases followed by melanoma, adenocarcinoma, sarcoma as well as basal cell carcinoma. $[4,5]$

The most common known etiology for development of vulvar tumors involves infection with the Human Papilloma Virus (HPV). [6] In this group of females there is an association with high-risk sexual activity in addition to 
smoking. In the remaining cases (most commonly elderly females with no apparent association to HPV infection) vulval cancer is commonly found on top of chronic dystrophic or inflammatory changes. [4]

The presenting symptoms are commonly local and include itching and pruritus, contact bleeding, offensive discharge, localized pain, mass or ulcer. Biopsy is required to establish the diagnosis. Other diagnostic measures include pelvic ultrasound, CT or MRI scans. In some cases further metastatic work up might be required. [4, 7]

Initial stage is considered the most important factor affecting the future treatment options and the following expected response to therapy. The overall 5-year survival rate of patients with stage I epidermoid invasive cancer might reach $85-90 \%$. Unfortunately, the expected survival rate falls with increasing stage; however, an approximate 5-year survival rate of $40 \%$ can be reached, even in patients with positive lymph node metastasis. [8, 9]

Other factors include histological grade and stromal invasion. In a review of the National Cancer Data Base, patients with positive inguinal lymph nodes for malignancy were found to have 5-year variable survival rates (About $64 \%$ with $2-\mathrm{cm}$ lesions and $43 \%$ with lesions measuring $>2 \mathrm{~cm}$ in size). In patients with primary tumors of any size, the survival rate was similar whether 1 lymph node was positive or 2-3 lymph nodes were positive (55\% vs $59 \%)$. However, the survival rate in patients with 4 or more positive nodes was only $33 \%$ at 5 years. [8]

Adequate groin treatment is the single most important factor in reducing mortality from vulvar tumors. It is recommended that both inguinal and femoral lymph nodes should be removed, and appropriate dissection should involve the removal of at least 8-10 nodes. [9]

Treatment options depend largely on the presenting stage and they include surgical resection, radiation (Brachytherapy and External beam therapy) as well as chemotherapy (CT). Early-stage vulvar cancer is primarily treated by surgical resection (radical vulvectomy and inguinofemoral lymphadenectomy). The surgical margins ideally should be $\geq 1$ $\mathrm{cm}$. Re-excision is considered if margins were found to be positive or less than $8 \mathrm{~mm}$. As an alternative, adjuvant radiation therapy may be considered rather than re-excision. [10]

Adjuvant radiation is determined based on pathological risk factors such as positive lympho-vascular invasion, bilateral malignant disease and positive lymph nodes (LN). Stage II disease with tumor extension up to the distal third of the urethra or vaginal distal third or with malignant anal involvement can be treated with radical local excision in addition to bilateral inguinofemoral lymphadenectomy. Radiation therapy to these regions can also be considered. A National Cancer Data Base (NCDB) analysed the data of 1797 patients with malignant vulval tumors who underwent radical surgery with confirmed positive inguinal nodal involvement and then treated with adjuvant radiation therapy, concluded that the addition of adjuvant chemotherapy to the management plan resulted in a $38 \%$ decline in mortality risk.[11]
In case of locally advanced vulvar cancers (namely: bulky stage III and stage IV), treatment options include radical surgery versus concurrent chemotherapy with radiation therapy. It was found that there is no statistically significant difference in overall survival (OS) or in treatment-related adverse events when chemoradiation (primary or neoadjuvant) was compared with primary radical surgical management.[12]

In case of metastatic vulvar cancer (stage IVB), chemotherapy treatment protocols used for metastatic vulvar cancer are similar to those used for metastatic cervical cancers, and combinations of radiotherapy with concurrent chemotherapy can be considered in some cases. [13]

\section{Patients and Methods}

\subsection{Study Design}

A retrospective analysis was done for the hospital records of patients diagnosed with vulval cancer and received treatment at Ain Shams University department of clinical oncology and nuclear medicine in the period from 1-1-2007 till 1-1-2012.

Sixty four patients with a histo-pathlogical proof of vulvar carcinoma were included in the analysis. The various risk factors were identified and correlated with treatment outcome and survival. Patient risk factors included: age, residence, smoking status, parity, offspring, menstrual status, family history of cancer, past history of cancer and age of onset of sexual activity. Pathological risk factors included: histology, grade, site, depth of invasion, post-operative margins, tumor size, positive lymph nodes, total dissected lymph nodes and stage of disease (TNM). Treatment factors studiedincluded surgery (biopsy versus radical surgery), groin lymph node dissection (LND), concurrent chemotherapy with radiotherapy versus radiotherapy alone. The data collected were analyzed and compared with the published literature. Clinical response was assessed using Response Evaluation Criteria in Solid Tumors criteria version 1.1. (RECIST 1.1)

Overall survival (OS) period was defined as the interval between the pathological diagnosis of the disease (surgery, or core biopsy) and death from any cause.

\subsection{Statistical Analysis}

All the collected Data was converted into codes and entered to the Statistical Package for Social Science (IBM SPSS) version 20. The qualitative data identified were given as numbers and percentages while quantitative data were presented as mean, median, standard deviations and ranges. Comparisons between two groups (with qualitative data) were done with Chi-square test and/or Fisher exact test (used instead of Chi-square test when the expected count was found less than 5. Kaplan Mayer analysis was used to assess the relation of overall survival (OS) with the other studied parameters. The confidence interval was set to $95 \%$ and the margin of error accepted was set to $5 \%$. So, the p-value was considered significant as the following: $\mathrm{P}>0.05$ : Non significant, $\mathrm{P}<0.05$ : Significant, $\mathrm{P}<0.01$ : Highly significant. 


\section{Results}

The median age of the 64 patients included in the study was 63 years (Range 43-68 years). Most of the patients had a good performance status; ECOG PS $1(81.3 \%)$. About $80 \%$ of the patients lived in rural areas. Most of the patients (75\%) patients were postmenopausal. All of the patients in the study weremultipara and had atleast 2 offspring. Regarding the age of onset of sexual activity, half the patients started at age of 18 years. Considering the first presentation, vulval mass was the most common (48.4\%), followed by vulval pain $(28.1 \%)$ and bleeding (23.4\%). All the reported cases showed squamous histology $(56.3 \%$ of cases werelow grade) with bilateral disease seen in $37.5 \%$. Unfortunately, all patients were advanced; stage III A (31.3\%) and III B (68.8\%). Twenty five patients had 4 positive lymph nodes (about 40\%), 11 patients with 5 +ve L.N (17.2\%), 14 patients with 6 +ve L.N (21.9\%), and 14 patients with 12 +ve L.N $(21.9 \%)$. Thirty one specimens were with negative margins (48.4\%) and 33 patients with positive margins $(51.6 \%)$.

Fourty patients underwent surgery with radical intent $(62.5 \%)$ and the other 24 were palliative surgery $(37.5 \%)$. Twenty eight patients had radical vulvectomy (43.8\%), 12 patients hemivulvectomy (18.8\%), 16 patients underwent excision (25\%), and the other 8 only did a biopsy (12.5\%). Thirty eight patients had lymph node dissection (59.4\%), in the other 26 patients, no dissection of lymph nodes was done $(40.6 \%)$.

As regards the radiation given, 42 patients had the radiation dose of 60 Gy (65.6\%), and the other 22 patients had 66Gy (34.4\%). Radiation was delivered by multi-energy linear accelerator using 3-D conformal technology with PERCISE planning system. Fourty eight patients had concurrent chemotherapy with the radiotherapy $(75 \%)$, the other 16 had radiation therapy only $(25 \%)$.

The median overall survival (OS) was 16.5 months (Range
7-20 months). Rural residence of the patient was associated with a favourable statistically significant OS of 17 months versus 10 months in patients from urban residence $(p=0.002)$. Pre menopausal patients had a statistically significant longer OS of 19 months versus 16 months in post menopausal patients $(\mathrm{p}<0.001)$. Higher number of offspring ( $\geq 5$ offspring) was associated with lower OS of 10 months as compared to 19 months in case of $<5$ offspring $(\mathrm{p}<0.001)$. As regard findings at initial clinical examination, patients presenting with ulcer had a lower OS (11 months) as compared to patients presenting with a mass (19 months, $p=0.001)$ and patients presenting with bilateral vulval disease were associated with the lower OS of 10 months versus 17 months in case of unilateral disease $(p=0.04)$. While patients with low grade disease experienced a better OS (19 months versus 10 months in patients with high grade, $p=0.001)$. Patients with $\geq 4$ positive lymph nodes were associated with unfavourable survival outcome (16 months) in comparison to those with less than 4 positive groin LN (17 months, $\mathrm{p}=0.047$ ). Patients with negative resection margins were associated with the highest OS (19 versus 10 months in case of positive margin, $\mathrm{p}<0.001)$. The depth of stromal invasion had an impact on survival, where an invasion $\geq 1 \mathrm{~cm}$ was associated with worse OS (17 versus 16 months in case of depth $<1 \mathrm{~cm}, \mathrm{p}=0.015$ ). The tumor size also affected OS where tumors $\geq 4 \mathrm{~cm}$ were associated with worse OS (10 months in comparison to 17 months iftumor size $<4 \mathrm{~cm}, \mathrm{p}=0.001$ ).

Other studied factors including radical versus palliative surgery, groin lymph node dissection, dose of radiation therapy, concurrent radiation and chemotherapy versus radiation only did not have a statistically significant impact on overall survival.

COX regression multivariate analysis showed that menstrual status, pathological grade and resection margins had an impact on survival.

Table 1. Descriptive data of the studied sample.

\begin{tabular}{llll}
\hline Factor Assessed & & No. & \% \\
\hline Age Groups & $41-50$ & 20 & 31.25 \\
(years) & $51-60$ & 0 & 0 \\
& $61-70$ & 44 & 68.75 \\
Performance (PS) & 1 & 52 & 81.3 \\
& 2 & 12 & 18.8 \\
Residence & Rural & 51 & 79.7 \\
Family History & Urban & 13 & 20.3 \\
Menstrual Status & No & 56 & 87.5 \\
& yes & 8 & 12.5 \\
Number of offspring & Post-menopause (Pre) & 75 \\
& Pre-menopause (Post) & 25 \\
& 2 & 48 & 12.5 \\
Age of Onset of Sexual Activity & 3 & 8 & 25 \\
& 4 & 16 & 12.5 \\
& 5 & 8 & 50 \\
Presentation & 16 & 32 & 15.6 \\
& 18 & 32 & 50.0 \\
\end{tabular}




\begin{tabular}{|c|c|c|c|}
\hline Factor Assessed & & No. & $\%$ \\
\hline \multirow{2}{*}{ Examination } & Mass (M) & 31 & 48.4 \\
\hline & Ulcer (U) & 33 & 51.6 \\
\hline \multirow{3}{*}{ Site } & Bilateral Labia Major & 24 & 37.5 \\
\hline & Clitorius & 10 & 15.6 \\
\hline & Unilateral Labium Major & 30 & 46.9 \\
\hline \multirow{2}{*}{ Grade } & Low Grade (1) & 28 & 43.8 \\
\hline & High Grade (2) & 36 & 56.3 \\
\hline \multirow{2}{*}{ Stage } & IIIA & 20 & 31.3 \\
\hline & IIIB & 44 & 68.8 \\
\hline \multirow{6}{*}{ Tumor size $(\mathrm{cm})$} & 3 & 21 & 32.8 \\
\hline & 4 & 12 & 18.8 \\
\hline & 5 & 10 & 15.6 \\
\hline & 8 & 1 & 1.6 \\
\hline & 9 & 18 & 28.1 \\
\hline & 10 & 2 & 3.1 \\
\hline \multirow{4}{*}{ Positive LN } & 4 & 25 & 39 \\
\hline & 5 & 11 & 17.2 \\
\hline & 6 & 14 & 21.9 \\
\hline & 12 & 14 & 21.9 \\
\hline \multirow{5}{*}{ Depth (cm) } & 0.7 & 3 & 4.7 \\
\hline & 0.8 & 7 & 10.9 \\
\hline & 0.9 & 7 & 10.9 \\
\hline & 1 & 33 & 51.6 \\
\hline & 1.5 & 14 & 21.9 \\
\hline \multirow{2}{*}{ Margin } & Negative (n) & 31 & 48.4 \\
\hline & Positive (y) & 33 & 51.6 \\
\hline \multirow{2}{*}{ Surgery Aim (Radical verus Not) } & $\mathrm{n}$ & 24 & 37.5 \\
\hline & $\mathrm{R}$ & 40 & 62.5 \\
\hline \multirow{4}{*}{ Surgery } & Biopsy & 8 & 12.5 \\
\hline & Excission & 16 & 25 \\
\hline & Hemivulvectomy & 12 & 18.8 \\
\hline & Radical Vulvectomy & 28 & 43.8 \\
\hline \multirow{2}{*}{ Groin LN Dissection } & $\mathrm{n}$ & 26 & 40.6 \\
\hline & $\mathrm{y}$ & 38 & 59.4 \\
\hline \multirow{2}{*}{ Radiation Dose } & $60 \mathrm{~Gy}$ & 42 & 65.6 \\
\hline & 66 Gy & 22 & 34.4 \\
\hline \multirow{2}{*}{ Concurrent Chemotherapy and Radiation } & $\mathrm{n}$ & 16 & 25 \\
\hline & $\mathrm{y}$ & 48 & 75 \\
\hline
\end{tabular}

Table 2. Descriptive data of String Variables in the studied population.

\begin{tabular}{|c|c|c|c|c|c|c|c|}
\hline & Age (years) & Offspring & Age of Onset of Sexual Activity (Years) & Tumor size (cm) & Positive LN & Depth (cm) & OS (months) \\
\hline Median & 63 & 3 & 18 & 4 & 5 & 1 & 16.5 \\
\hline Std. Deviation & 8.141 & 1.153 & 1.397 & 2.606 & 3.094 & 0.2478 & 4.9618 \\
\hline Minimum & 43 & 2 & 5 & 3 & 4 & 0.7 & 7 \\
\hline Maximum & 68 & 5 & 16 & 10 & 12 & 1.5 & 20 \\
\hline
\end{tabular}

Table 3. Factors associated with an impact on overall survival.

\begin{tabular}{|c|c|c|c|c|}
\hline Factor & & Median OS (months) & 95\% CI (months) & $p$-value \\
\hline \multirow{2}{*}{ Residance } & Rural (R) & 17 & $16.385-17.615$ & \multirow{2}{*}{0.002} \\
\hline & Urban (U) & 10 & $8.777-11.223$ & \\
\hline \multirow{2}{*}{ Menstrual Status } & Postmenopause (post) & 16 & $12.103-19.897$ & \multirow{2}{*}{$<0.001$} \\
\hline & Premenopause (pre) & 19 & $17.693-20.307$ & \\
\hline \multirow{2}{*}{ Offspring } & $<5$ & 19 & $18.040-19.960$ & \multirow{2}{*}{$<0.001$} \\
\hline & $\geq 5$ & 10 & $8.073-11.927$ & \\
\hline \multirow{2}{*}{ Clinical Presentation } & Mass (M) & 19 & $16.853-21.147$ & \multirow{2}{*}{0.001} \\
\hline & Ulcer (U) & 11 & $7.483-14.517$ & \\
\hline \multirow{2}{*}{ Disease Lateralization } & Bilateral (bi) & 10 & $7.952-12.048$ & \multirow{2}{*}{0.04} \\
\hline & Unilateral (uni) & 17 & $16.604-17.396$ & \\
\hline \multirow{2}{*}{ Pathological Grade } & Low grade (1) & 19 & $17.829-20.171$ & \multirow{2}{*}{$<0.001$} \\
\hline & High grade (2) & 10 & $7.850-12.150$ & \\
\hline \multirow{2}{*}{ Tumor Size (cm) } & $\geq 4(\mathrm{n})$ & 10 & $6.619-13.381$ & \multirow{2}{*}{0.001} \\
\hline & $<4(\mathrm{y})$ & 17 & $13.636-20.364$ & \\
\hline \multirow{3}{*}{$\begin{array}{l}\text { Depth of Stromal invasion } \\
\text { (cm) } \\
\text { Resection Margins }\end{array}$} & $<1$ & 17 & $14.983-19.017$ & \multirow{2}{*}{0.015} \\
\hline & $\geq 1$ & 16 & $7.984-24.016$ & \\
\hline & Negative (n) & 19 & $18.523-19.477$ & $<0.001$ \\
\hline
\end{tabular}




\begin{tabular}{lllll}
\hline Factor & & Median OS (months) & 95\% CI (months) & $p$-value \\
\hline \multirow{3}{*}{ Positive Groin Lymph nodes } & Positive (y) & 10 & $8.010-11.990$ & \\
& $<4$ & 16 & $12.399-19.601$ & 0.047 \\
\hline
\end{tabular}

Table 4. COX regression analysis for the studied variables in univariate analysis.

\begin{tabular}{|c|c|c|c|c|c|c|}
\hline Factor & B & SE & Wald & df & Sig. & $\operatorname{Exp}(B)$ \\
\hline Residence & .478 & .547 & .764 & 1 & .382 & 1.614 \\
\hline Menstrual Status & 1.129 & .487 & 5.379 & 1 & .020 & 3.091 \\
\hline Offspring & -.461 & .389 & 1.404 & 1 & .236 & .631 \\
\hline Disease Lateralization & 1.127 & .602 & 3.496 & 1 & .062 & 3.085 \\
\hline Grade & -2.320 & .648 & 12.822 & 1 & .000 & .098 \\
\hline Tumor size & -.123 & .514 & .057 & 1 & .811 & .884 \\
\hline Positive Groin Lymph nodes & .422 & .492 & .737 & 1 & .391 & 1.526 \\
\hline Depth of Stromal invasion & -.135 & .405 & .111 & 1 & .739 & .874 \\
\hline Resection Margins & -1.414 & .477 & 8.797 & 1 & .003 & .243 \\
\hline
\end{tabular}

\section{Discussion}

Primary vulval tumors are the $20^{\text {th }}$ most common female cancers, mainly seen in age groups 50-70 years. [14] Okolo et al. examined 78 cases of vulvar cancer from 1981 to 2008. The mean age in this clinical study was 49.7 years with a peak incidence found in the fifth decade. [15] In a study by Singh et al. which comprised 41 cases of vulval cancer, the mean age was 52 years, but the peak incidence was observed in the sixth and seventh decades. Incidence is significantly high in multiparous and postmenopausal women, however, not related to survival. [16]

These findings were confirmed by our study where the all the studied females were multipara and $75 \%$ were postmenopause. In addition, the median age was 63 years, however the sample included patients less than 50 years (15.2\%). However, in our study, Pre menopausal patients had a statistically significant longer OS of 19 months versus 16 months in post menopausal patients $(\mathrm{p}<0.001)$. Higher number of offspring ( $\geq 5$ offspring) was associated with lower OS of 10 months as compared to 19 months in case of $<5$ offspring $(\mathrm{p}<0.001)$.

The most common type of vulvar cancer is squamous cell carcinoma (SCC) accounting for more than $90 \%$ of the cases; the remaining types are rare and include: melanoma, adenocarcinoma, sarcoma and basal cell carcinoma. Okolo et al. showed that $73.61 \%$ of vulvar cancers included in their study were squamous cell type (SCC). [15] Similarly, in a study by Singh et al, SCC accounted for $97.56 \%$ of the cases. [16]

Furthermore, a study from Tunisia by Kehila et al. showed similar findings, which is very similar to the results of our study where all patients were SCC. [17]

Kosary et al. studied the prognostic impact of FIGO stage, histology, histologic grade, age and race in survival for cancers of the female gynecological (cervix, endometrium, ovary, vulva, vagina) using cases obtained from the National Cancer Institute's Surveillance, Epidemiology, and End Results (SEER) program that were diagnosed between 1973 and 1987. [18]
Paladini et al. published a study of 75 patients with inguinal and/or pelvic lymph node malignant metastases from vulval cancer of squamous histology. Among the parameters examined in this study were: size as well as location of the primary cancer $(\mathrm{T})$, depth of invasion of the stromal tissues, histological grade, positive cancerous lympho-vascular space involvement (LVSI), local immune response, FIGO stage, number of involved lymph nodes (LN). Among the variables related to the primary tumors, only size of the primary tumor and LVSI had an impact on with survival $(\mathrm{P}<0.003$ and $\mathrm{P}<$ 0.02 , respectively). [19] These findings are similar to our results where we found that patients with primary tumors $\geq 4$ $\mathrm{cm}$ were associated with worse OS (10 months in comparison to 17 months if tumor size $<4 \mathrm{~cm}, \mathrm{p}=0.001)$.

While some clinical studies did not observe any association between the number of metastatic lymph nodes and the risk of recurrence, other trials have identified that two or more positive lymph nodes, extracapsular spread as well as metastatic lesions were poor prognostic factors. [20]

More recent clinical studies and reviews show that even one positive lymph-node metastasis significantly affects prognosis negatively compared with lymph node-negative patients and in a further analysis by Woelber et al., the number of affected nodes was highly statistically significant as a prognostic factor in the patients who did not receive adjuvant treatment.[21] What is interesting in our analysis is that we evaluated the significance of the number of lymph node metastases in a group of patientswho were lymph node positive while most previous studies compared lymph node positive with negative patients in general.

\section{Conclusion}

We have found that patients with urban residence have been linked with more aggressive disease leading to decrease of OS. The age of onset of intercourse did not affect survival as we were expecting, however, multiple offspring which could be related to more frequent intercourse had an effect on survival. The offered treatment modalities did not show a superiority probably because all the patients presented in an advanced stage. The anatomical nature of this cancer might 
be the cause in delayed diagnosis which warrants health education projects for early detection. Further studies are required to assess the risk factors for development of vulval cancer in Egyptian patients.

\section{References}

[1] Howlader N, Noone AM, Krapcho M, et al. SEER Cancer Statistics Review, 1975-2012, National Cancer Institute. Bethesda, MD: April 2015.

[2] American Cancer Society. Cancer Facts and Figures 2018. Atlanta, Ga: American Cancer Society; 2018.

[3] Ibrahim AS, Khaled HM, Mikhail N, Baraka H and Kamel H. Cancer Incidence in Egypt: Results of the National Population-Based Cancer Registry Program. J Cancer Epidemiol. 2014; 2014: 437971

[4] Eifel PJ, Berek JS, Markman MA. Cancer of the cervix, vagina, and vulva. In: DeVita VT Jr., Lawrence TS, Rosenberg SA, editors. Cancer: Principles and Practice of Oncology. $9^{\text {th }}$ ed. Philadelphia, PA: Lippincott Williams \& Wilkins; 2011. p. 1311-44.

[5] Hacker NF, Eifel PJ, van der Veldenc J. FIGO cancer report 2012. Cancer of the vulva. Int J GynecolObstet 2012; 119 Suppl 2: S90-6.

[6] Rakislova N, Saco A, Sierra A, Del Pino M, Ordi J. Role of Human Papillomavirus in Vulvar Cancer. Adv Anat Pathol. 2017 Jul; 24 (4): 201-214.

[7] Committee Opinion No. 675 Summary: Management of Vulvar Intraepithelial Neoplasia. Obstet Gynecol. 2016 Oct. 128 (4): 937-8.

[8] Creasman WT, Phillips JL, Menck HR. The National Cancer Data Base report on early stage invasive vulvar carcinoma. The American College of Surgeons Commission on Cancer and the American Cancer Society. Cancer. 1997 Aug 1. 80 (3): 505-13.

[9] Hacker NF. Vulvar cancer. In: Berek JS, Hacker NF, editors. Berek and Hacker's Gynecologic Oncology. $5^{\text {th }}$ ed. Philadelphia: Lippincott Williams \& Wilkins; 2009. p. 536-75.

[10] Khanna N, Rauh LA, Lachiewicz MP, Horowitz IR. Margins for cervical and vulvar cancer. J Surg Oncol. 2016 Mar. 113 (3): $304-9$
[11] Gill BS, Bernard ME, Lin JF, Balasubramani GK, Rajagopalan MS, Sukumvanich P, et al. Impact of adjuvant chemotherapy with radiation for node-positive vulvar cancer: A National Cancer Data Base (NCDB) analysis. Gynecol Oncol. 2015 Jun. 137 (3): 365-72.

[12] Shylasree TS, Bryant A, Howells RE. Chemoradiation for advanced primary vulval cancer. Cochrane Database Syst Rev. 2011 Apr 13.

[13] Gadducci A, Cionini L, Romanini A, Fanucchi A, Genazzani AR. Old and new perspectives in the management of high-risk, locally advanced or recurrent, and metastatic vulvar cancer. Crit Rev Oncol Hematol. Ireland: 2006. 227-41.

[14] Nicoletto MO, Parenti A, Del Bianco P, Lombardi G, Pedrini L, Pizzi S, Carli P, Della Palma M, Pastorelli D, Corti L, Becagli L. Vulvar cancer prognostic factors. Anticancer Res. 2010 Jun; 30 (6): 2311-7.

[15] Okolo CA, Odubanjo MO, Awolude OA, Akang EE. A review of vulvar and vaginal cancers in Ibadan, Nigeria. N Am J Med Sci 2013; 6: 76-81.

[16] Singh N, Negi N, Srivastava K, Agarwal G. A cohort study of vulvar cancer over a period of 10 years and review of literature. Indian J Cancer 2016; 53: 412-5.

[17] Kehila M, ChanoufiM. Vulvar cancer in Tunisia: Epidemiological and clinicopathological features multicentric study. Journal of the Egyptian National Cancer Institute Volume 29, Issue 2, June 2017, Pages 95-98.

[18] Kosary CL. FIGO stage, histology, histologic grade, age and race as prognostic factors in determining survival for cancers of the female gynecological system: an analysis of 1973-87 SEER CASES of cancers of the endometrium, cervix, ovary, vulva and vagina. Seminars in surgical oncology 10 (1), 31-46, 1994.

[19] Paladini D, Cross P, Lopes A, Monaghan J. Prognostic significance of lymph node variables in squamous cell carcinoma of the vulva. Cancer 74 (9), 2491-2496, 1994.

[20] Lataifeh I., Carraro Nascimento M., Nicklin J., Perrin L., Crandon A., Obermair A. (2004) Patterns of recurrence and disease-free survival in advanced squamous cell carcinoma of the vulva. Gynecol Oncol 95: 701-705.

[21] Oonk M., van Hemel B., Hollema H., de Hullu J., Ansink A., Vergote I., et al. (2010) Size of sentinel-node metastasis and chances of non-sentinel-node involvement and survival in early stage vulvar cancer: results from GROINSS-V, a multicentre observational study. Lancet Oncol 11: 646-652. 